\title{
Educação à Distância em Nefrologia na Amazônia: Processos e Resultados
}

\author{
Distance Education in Nephrology in the \\ Amazon Region: Processes and Results
}

\author{
Leandro Arthur Diehl \\ Carlos Perez Gomes \\ Gisele de Vasconcelos Sary \\ Hélia Cardoso Gomes da Rocha ${ }^{I}$ \\ Luís Marcelo Aranha Camargo ${ }^{l}$ \\ Pedro Alejandro Gordan
}

\section{PALAVRAS-CHAVE \\ - Educação à Distância. \\ - Nefrologia. \\ - Aprendizagem Baseada em Problemas. \\ - Educação Superior. \\ - Educação Médica.}

\section{KEYWORDS}

- Distance Education.

- Nephrology.

- Problem-Based Learning.

- Higher Education.

- Medical Education.

Reencaminhado em: 02/07/2012

Aprovado em: 19/08/2012

REVISTA BRASILEIRA DE EDUCAÇÃO MÉDICA

\section{RESUMO}

A carência de docentes qualificados na Região Amazônica levou à adoção de tecnologias de Educação à Distância para organizar a disciplina de Nefrologia do quarto ano do curso de graduação em Medicina da Faculdade São Lucas (FSL), localizada em Porto Velho (RO). Neste trabalho, descrevemos a construção do curso na plataforma Moodle, usando uma estrutura de módulos para discutir os principais tópicos de Nefrologia em fóruns de discussão assíncronos online com base em problemas clínicos ilustrativos, e mostramos os resultados do curso, que já foi realizado com três turmas de alunos, bem como as avaliações da metodologia, realizadas pelos alunos e pela instituição.

\section{ABSTRACT}

The relative lack of qualified teachers in the Amazon Region led to the adoption of Distance Education technologies in order to implement Nephrology classes in the fourth year of the medical course in São Lucas College (Faculdade de São Lucas), located in Porto Velho, Rondonia. In this paper, we describe the construction of the course on the Moodle platform, using a modular structure to discuss the main topics of Nephrology in online asynchronous forums based on illustrative clinical problems, and we also show the results of the classes, which has already been completed with 3 groups of medical students, and the evaluation of the methodology by the students and by the institution. 


\section{INTRODUÇÃO}

A implantação de cursos de Medicina em grande número e em várias regiões do Brasil gerou uma série de problemas não imediatamente antecipados, como a necessidade de docentes qualificados, principalmente de especialidades e em regiões de acesso limitado à capacitação.

Para uma melhor formação de médicos generalistas, não há como privá-los de conhecimentos básicos em Clínica Médica, por exemplo. Também não podemos criar ilusões de que existem professores de Clínica Médica disponíveis em número e com qualidade adequada para atender a esta demanda. Portanto, na grande maioria das escolas médicas do Brasil, temas de Clínica Médica são abordados por especialistas com formação clínica de excelência.

A Nefrologia tornou-se especialidade médica no fim dos anos 1950 e começo da década de 1960, por necessidade e estímulo de grandes professores de Clínica Médica, como o professor Luiz V. Décourt, de cuja cátedra (2ª Clínica Médica da USP) a Nefrologia brasileira é originária.

Na Região Amazônica, e em Porto Velho (RO) em particular, a existência de especialistas em Nefrologia é exígua, e os poucos nefrologistas estão empenhados em atender à demanda de seus pacientes e dar cobertura às necessidades do SUS. Sua vocação se restringe à assistência, sem que haja tempo ou mesmo qualificação acadêmica adequada para a carreira universitária.

Assim como as outras faculdades locais, a Faculdade São Lucas (FSL) se deparou com a dificuldade de ter cobertura acadêmica nefrológica constante e ininterrupta para seus alunos, considerando a importância dos temas gerais de Nefrologia, como distúrbios hidroeletrolíticos e ácido-básicos, insuficiência renal aguda dirigida a patologias locais, como malária, dengue e outras arboviroses, leptospirose e acidentes com animais peçonhentos. Além disso, noções de prevenção de doença renal crônica e seu encaminhamento, pois a cobertura desta patologia na região é a menor do País.

Como a cobertura docente nefrológica era intermitente e esporádica, o coordenador do curso de Medicina da FSL, Prof. Dr. Luís Marcelo Aranha Camargo, sugeriu a realização de um curso semipresencial, inicialmente sob a forma de Curso de Extensão em Nefrologia, que garantisse a cobertura durante todo o período em que era ministrada a disciplina de Clínica Médica III, no sétimo e oitavo semestres (quarto ano) do curso de Medicina da instituição.

\section{OBJETIVOS}

Relatar a experiência relacionada ao desenho e à realização de um curso semipresencial de Nefrologia para estudantes do curso de graduação em Medicina, levando em conta sua meto- dologia, estrutura acadêmica, logística, métodos instrucionais, avaliação institucional e acadêmica do curso e avaliação dos estudantes.

\section{METODOLOGIA}

A metodologia empregada no curso de Nefrologia para alunos do quarto ano de Medicina da FSL, uma instituição privada, foi a Aprendizagem Baseada em Problemas (ABP). A ABP constitui um modelo de ensino de valorização humanística por meio de uma pedagogia renovada, em que o aluno é a peça central, e o processo de aprendizagem é mais importante que o próprio ensino, ou seja, o objetivo é "aprender a aprender"1. A ABP foi inspirada em movimentos como a Escola Nova e a Escola Ativa, subsidiadas filosoficamente por grandes pensadores como Piaget, Jürgen Habermas, Montessori, Paulo Freire e Anisio Teixeira. Nesse método, os "estudantes se deparam inicialmente com um problema, o qual é sucedido por uma investigação em um processo de aprendizagem centrada no estudante ${ }^{2-5}$, como descrito por Stewart Mennin e Gerard Majoor ${ }^{6}$.

Ambos, conteúdo e processo de aprendizagem, são enfatizados na ABP. Embora muitas variantes do método ABP tenham sido desenvolvidas nos últimos 30 anos, seus elementos essenciais permanecem relativamente constantes. Incontestável, em ABP, é que o problema vem primeiro sem leituras prévias, aulas expositivas ou pesquisa, servindo como um incentivo para a necessidade de conhecer. Na ABP, o foco do ensino é transferido da transmissão tradicional e passiva de conteúdos pelo professor para o desenvolvimento da aprendizagem ativa do aluno; este passa a ser mais observador e questionador e pode interagir mais, tanto com o professor quanto com os demais alunos. No nosso caso, essa interação é realizada à distância, usando recursos de informática.

Dessa forma, a metodologia deste curso vai ao encontro das Diretrizes Curriculares Nacionais do Curso de Graduação em Medicina ${ }^{7}$, que preconizam a necessidade de formação de um médico mais autônomo e crítico na sociedade, e que seja capaz de atuar nos diversos níveis de atenção à saúde, principalmente na Atenção Básica. O conteúdo do curso contemplou as doenças renais mais prevalentes na sociedade e que devem ser de conhecimento de todo médico generalista. Além disso, para aproximar os alunos ainda mais da realidade local de Rondônia e da região amazônica, parte do conteúdo deste curso foi desenvolvida com ênfase em doenças endêmicas locais e que também acometem os rins, tais como malária, febre amarela, leptospirose, dengue e acidentes com animais peçonhentos.

O curso semipresencial de Nefrologia foi estruturado em duas etapas: aulas presenciais, com uma semana de duração, e 
aulas e discussões por ensino à distância (EAD), com dez semanas de duração. Esta segunda etapa de EAD foi desenvolvida em plataforma Moodle, de forma que os alunos, mediante senha individual, pudessem participar do curso em horários e locais de sua preferência. No EAD, a turma era dividida em grupos, e cada um deles (de seis a dez alunos) ficava sob orientação de um professor-tutor durante todo o período do curso.

O conteúdo programático do curso foi dividido em módulos. Cada módulo consistia em uma aula síncrona expositiva por webconferência (sendo que todas as aulas expositivas também foram previamente gravadas em vídeo e distribuídas em DVD aos alunos), uma aula introdutória para orientar o estudo, um problema clínico, lista de objetivos do módulo, slides das aulas em PDF para download e impressão, recursos didáticos, como vídeos e links para referências bibliográficas, fórum de discussão e avaliação final. Todo módulo era iniciado por um caso (ou problema) clínico relacionado ao tema do módulo. Com base neste problema, abria-se um fórum de discussão assíncrona, disponível na plataforma Moodle, entre alunos e professores, com quatro a sete dias de duração, permitindo interações aluno-professor e aluno-aluno acerca da investigação diagnóstica, prognóstico e tratamento dos pacientes acometidos pela doença renal em questão. Todo o conteúdo das discussões dos fóruns ficava gravado e disponível, ao final da discussão, para todos os participantes. A avaliação era feita, em cada módulo, de forma individual e à distância, de duas maneiras: pela participação do aluno na discussão e pelas respostas a um teste online com questões de múltipla escolha, disponibilizado apenas no último dia do módulo. Além da avaliação à distância, duas provas escritas presenciais eram aplicadas, na metade e no final do curso, abrangendo todo o conteúdo apresentado. Todos os módulos também ofereciam um espaço (fórum) para que o aluno pudesse enviar comentários, críticas e sugestões, possibilitando alterações dinâmicas para melhoria das atividades à distância durante o curso. A Figura 1 apresenta um exemplo da estrutura de um módulo na plataforma Moodle.

Paralelamente aos módulos, na última turma do curso foi criado um perfil, na rede social Facebook, de um paciente virtual, hipotético, portador de doença renal crônica, para que os alunos, desde o inicio do curso e de forma mais descontraída e informal, livres da pressão da avaliação por notas, pudessem interagir com uma pessoa acometida por uma nefropatia. Este paciente virtual tinha suas manifestações no Facebook elaboradas pelos professores, de modo que se instigasse a curiosidade dos alunos sobre a realidade de uma pessoa que precisa fazer exames, ir às consultas, enfim, continuar vivendo o processo saúde-doença em nossa realidade.
FIGURA 1

Exemplo de módulo do curso semipresencial de Nefrologia, como visualizado na plataforma Moodle

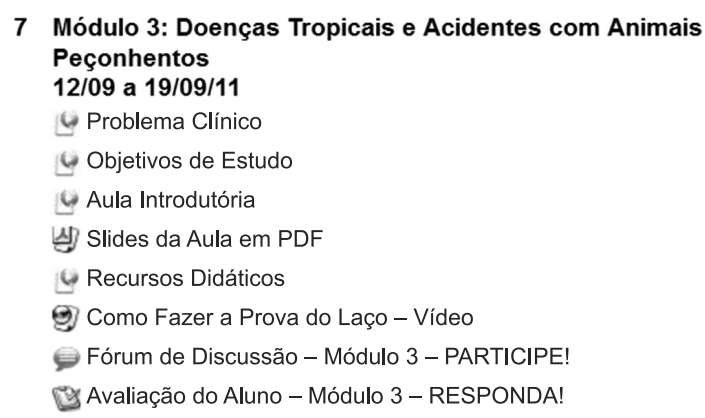

Ao final de cada edição do curso semipresencial de Nefrologia, os alunos foram convidados a responder a um questionário para avaliação do curso, contendo questões de múltipla escolha (escala de Likert) e questões de resposta aberta (texto livre), a fim de captar as impressões que os alunos tiveram da metodologia utilizada e do seu aprendizado durante o curso.

A submissão a um Comitê de Ética em Pesquisa, neste caso, é dispensável, por se tratar da mera descrição e avaliação de uma experiência única, não generalizável, conforme orientações da Comissão Nacional de Ética em Pesquisa (Conep) ${ }^{8}$.

\section{RESULTADOS}

Até a metade de 2011, três turmas do curso de graduação em Medicina da FSL participaram do curso semipresencial de Nefrologia, como parte da disciplina curricular Clínica Médica III, inserida no sétimo semestre do curso. Havia, no total, 175 alunos inscritos - 37 no primeiro semestre de 2010; 77 no segundo semestre de 2010; e 61 no primeiro semestre de 2011 dos quais 160 completaram todas as atividades e avaliações do curso. Apresentamos a seguir os resultados da avaliação qualitativa dos alunos sobre a metodologia empregada no curso.

Em relação às impressões dos alunos sobre o curso semipresencial de Nefrologia, a maioria dos alunos nos três grupos aprovou a experiência. Os componentes do curso que receberam melhor avaliação dos alunos foram: conteúdo geral do curso, equipe de professores e recursos didáticos oferecidos para estudo nos módulos (Tabela 1). Os componentes que receberam a pior avaliação foram: qualidade da imagem, do som e da sala utilizada para as aulas síncronas por webconferência, tempo disponível para estudo e participação nos fóruns e aproveitamento do ensino pelos alunos. Não houve diferença significativa entre as respostas dos alunos a esse questionário de avaliação do curso quando comparados os três grupos (dados não mostrados). 
TABELA 1

Respostas dos alunos às questões para avaliação das atividades do curso semipresencial de Nefrologia $(n=175)$

\begin{tabular}{|c|c|c|c|c|c|}
\hline \multirow{2}{*}{ Item avaliado } & \multicolumn{5}{|c|}{ Respostas } \\
\hline & Ótimo/Muito bom & Bom & Regular & Ruim & Muito ruim/Péssimo \\
\hline \multicolumn{6}{|c|}{ A respeito do curso, de maneira geral } \\
\hline Impressão geral & $54 \%$ & $34 \%$ & $11 \%$ & $1 \%$ & 0 \\
\hline Conteúdo & $82 \%$ & $15 \%$ & $3 \%$ & 0 & 0 \\
\hline Metodologia & $46 \%$ & $33 \%$ & $15 \%$ & $3 \%$ & $3 \%$ \\
\hline Equipe docente & $89 \%$ & $9 \%$ & $1 \%$ & 0 & $1 \%$ \\
\hline Aproveitamento & $29 \%$ & $39 \%$ & $23 \%$ & $7 \%$ & $2 \%$ \\
\hline \multicolumn{6}{|c|}{ A respeito das aulas dadas durante o curso } \\
\hline Nível e profundidade & $69 \%$ & $24 \%$ & $5 \%$ & $1 \%$ & $1 \%$ \\
\hline Slides e recursos audiovisuais & $59 \%$ & $31 \%$ & $8 \%$ & $1 \%$ & $1 \%$ \\
\hline \multicolumn{6}{|c|}{ A respeito das aulas dadas por webconferência } \\
\hline Qualidade da imagem & $28 \%$ & $41 \%$ & $22 \%$ & $5 \%$ & $4 \%$ \\
\hline Qualidade do som & $14 \%$ & $18 \%$ & $42 \%$ & $18 \%$ & $8 \%$ \\
\hline Qualidade da sala de aula & $40 \%$ & $41 \%$ & $11 \%$ & $6 \%$ & $2 \%$ \\
\hline \multicolumn{6}{|c|}{ A respeito dos módulos temáticos on-line } \\
\hline Impressão geral & $52 \%$ & $28 \%$ & $13 \%$ & $3 \%$ & $4 \%$ \\
\hline Facilidade de acesso & $52 \%$ & $30 \%$ & $14 \%$ & $2 \%$ & $2 \%$ \\
\hline Conteúdo & $76 \%$ & $20 \%$ & $3 \%$ & $1 \%$ & 0 \\
\hline Recursos didáticos & $69 \%$ & $25 \%$ & $4 \%$ & $1 \%$ & $1 \%$ \\
\hline Tempo para estudo & $21 \%$ & $29 \%$ & $37 \%$ & $8 \%$ & $5 \%$ \\
\hline Discussões no fórum & $63 \%$ & $25 \%$ & $10 \%$ & $1 \%$ & $1 \%$ \\
\hline Questionários & $59 \%$ & $28 \%$ & $8 \%$ & $2 \%$ & $3 \%$ \\
\hline Impacto no estímulo para estudo & $50 \%$ & $30 \%$ & $11 \%$ & $4 \%$ & $5 \%$ \\
\hline
\end{tabular}

No final do curso também foi aplicado um questionário sobre as impressões dos alunos em relação às características da metodologia empregada. Uma pergunta foi sobre que tipo de aula teria contribuído mais para o aprendizado: $56 \%$ dos alunos responderam que foram as aulas gravadas em vídeo (disponibilizadas desde o início do curso a todos os alunos, em um DVD), 35\% indicaram as aulas presenciais, e apenas $9 \%$ elegeram as aulas por webconferência. Solicitou-se também que comparassem o curso semipresencial de Nefrologia com as atividades didáticas tradicionais vivenciadas pelos alunos ao longo da sua trajetória escolar. Mais da metade dos alunos afirmou que o curso semipresencial foi tão bom quanto as atividades tradicionais ou um pouco melhor (Tabela 2). Quando perguntados sobre se aprenderiam mais num curso tradicional ou no curso semipresencial de Nefrologia, 48\% dos alunos afirmaram que aprenderiam mais no curso semipresencial, enquanto $35 \%$ afirmaram que aprenderiam mais num curso tradicional, e os restantes $17 \%$ julgaram que aprenderiam da mesma forma em ambos. Novamente, não houve diferenças significativas entre as respostas dos três grupos.
TABELA 2

Respostas dos alunos às questões sobre comparação do curso semipresencial de Nefrologia com as atividades tradicionais de ensino $(n=175)$

\begin{tabular}{lccccc}
\hline \multicolumn{1}{c}{ Item avaliado } & \multicolumn{5}{c}{ Respostas } \\
\cline { 2 - 6 } & $\begin{array}{c}\text { Muito } \\
\text { melhor }\end{array}$ & $\begin{array}{c}\text { Pouco } \\
\text { melhor }\end{array}$ & $\begin{array}{c}\text { Seme- } \\
\text { lhante }\end{array}$ & $\begin{array}{c}\text { Pouco } \\
\text { pior }\end{array}$ & $\begin{array}{c}\text { Muito } \\
\text { pior }\end{array}$ \\
\hline $\begin{array}{l}\text { Metodologia do curso } \\
\text { semipresencial }\end{array}$ & $13 \%$ & $26 \%$ & $37 \%$ & $20 \%$ & $4 \%$ \\
$\begin{array}{l}\text { Aproveitamento no } \\
\text { curso semipresencial }\end{array}$ & $12 \%$ & $23 \%$ & $38 \%$ & $22 \%$ & $5 \%$ \\
$\begin{array}{l}\text { Dificuldade do curso } \\
\text { semipresencial }\end{array}$ & $5 \%$ & $22 \%$ & $38 \%$ & $32 \%$ & $3 \%$ \\
\hline
\end{tabular}

Uma questão adicional direcionada aos alunos foi a seguinte: "Se um outro aluno, seu amigo, perguntasse a você se vale a pena fazer este curso semipresencial, o que você responderia?". As respostas foram: "sem dúvida, é melhor que o tradicional" (18\%); "vale a pena e é tão bom quanto o tradicional" $(45 \%) ;$ " vale a pena somente se você não puder fazer o curso 
TABELA 3

Principais pontos fortes, pontos fracos e sugestões para melhoramento do curso $(n=175)$

\begin{tabular}{lllll}
\hline \multicolumn{1}{c}{ Pontos fortes } & $\%$ & Pontos fracos & $\%$ & \multicolumn{1}{c}{ Sugestões } \\
\hline Discussões no fórum & 30 & Equipamento para webconferência & 29 & Melhorar o equipamento da sala de webconferência \\
Equipe docente & 23 & Falta de tempo para participar do fórum & 17 & Começar o curso mais cedo, no início do semestre \\
Disponibilidade e acesso aos docentes & 21 & Curso muito curto ou de início muito tardio & 10 & Mais aulas presenciais \\
Recursos didáticos dos módulos & 15 & Falta de aulas práticas e/ou ambulatório & 5 & Aumentar o tempo para participação no fórum \\
Aulas gravadas em vídeo & 14 & & Aumentar a duração do curso \\
Aulas presenciais & 10 & Mais aulas práticas e/ou ambulatório & \\
Estímulo ao estudo & 9 & & & \\
Casos clínicos (problemas) & 6 & & & \\
Conteúdo do curso & 6 & & & \\
Questionários online & 5 & & & \\
Dinâmica das discussões & 5 & & & \\
\hline
\end{tabular}

Obs.: São exibidas apenas as respostas citadas por mais de $5 \%$ dos alunos. As questões eram de resposta livre, e cada aluno podia dar mais de uma resposta.

tradicional" (30\%); "vale a pena, pois exige menos esforço" ( $2 \%)$; e "não vale a pena; é melhor fazer o tradicional" (5\%).

Os principais pontos fortes, pontos fracos e as sugestões dos alunos para melhoramento do curso, indicados pelos três grupos, estão listados na Tabela 3.

\section{DISCUSSÃO}

Este é o primeiro relato de experiência sobre a realização de um curso semipresencial de Nefrologia ministrado no Brasil para estudantes de graduação em Medicina e é particularmente importante porque envolve uma região longínqua dos grandes centros e que faz parte da Amazônia Legal.

A Nefrologia é considerada uma especialidade médica de "tecnologia leve-dura" que envolve conhecimentos básicos avaliados como difíceis. Uma característica a distingue de outras especialidades clínicas: seu grande envolvimento em temas gerais e muito prevalentes na sociedade atual, nas áreas tanto de medicina de urgência/emergência e terapia intensiva, quanto de enfermidades crônicas.

Para assegurar que os conhecimentos básicos necessários fossem discutidos adequadamente, a primeira parte do curso foi ministrada de maneira tradicional, com aulas teóricas e discussão de casos com a presença de dois docentes. Uma avaliação teórica precedeu sempre a segunda parte do curso à distância (EAD). No segmento de EAD foi utilizada metodologia ativa de aprendizagem, com discussões de casos clínicos em pequenos grupos por meio de fóruns especialmente desenhados para esta finalidade. É interessante salientar que detectamos um problema muito importante: a pouca familiaridade desta população de estudantes da FSL com a língua inglesa, de forma que tivemos que adaptar os recursos didáticos encontrando material original e de revisões em língua portuguesa. Este fato nos limitou em relação à oferta de referências biblio- gráficas e de multimídia para cada módulo, e, portanto, à qualidade intrínseca de conteúdo.

Dominguez et al. ${ }^{9}$ descreveram que a avaliação do processo ensino-aprendizagem significa:

[...] estabelecer a gama de conhecimentos e habilidades que um indivíduo precisa ter atingido num certo estágio de sua carreira; estimar de forma precisa o nível dos alunos; oferecer informações sobre seu progresso; alterar o comportamento em relação à aprendizagem; motivar os alunos conscientizando-os sobre a importância do que estão aprendendo; e fornecer informações sobre a adequação do currículo aos professores e diretores.

Para alcançar esses objetivos de avaliação das competências adquiridas pelos estudantes, não é suficiente fazer apenas uma avaliação tradicional, somativa, centrada no professor, com prova teórica ao final do curso. Deve-se fazer, preferencialmente, uma avaliação mais formativa, centrada no aluno e contínua - ao longo de todo o curso - , fornecendo, assim, mecanismos de feedback entre alunos e professores/tutores. Portanto, no planejamento deste curso, levamos em consideração não somente a avaliação cognitiva discente, mas também (e principalmente) a avaliação do programa pelos estudantes, contemplando as preferências dos alunos, os problemas educacionais e de logística. Por intermédio desse feedback, foi possível modificar alguns aspectos da metodologia ao longo de cada curso. Por exemplo, a experiência inicial de manter aulas síncronas por webconferência (por meio do software livre Vsee) com a turma inteira reunida em auditório (em data e horário predeterminados na abertura dos módulos) se mostrou ineficaz. Isto ocorreu tanto por problemas técnicos e de logística quanto por desinteresse progressivo dos alunos, já que tinham em seu poder todas as aulas pré-gravadas para utilizá-las 
quando lhes aprouvesse, isto é, em seus ambientes e horários de escolha. Por outro lado, a discussão síncrona de casos, sugerida na própria avaliação dos alunos em relação ao curso (vide Tabela 1), não nos pareceu essencial, pois os fóruns escritos (assíncronos ou não simultâneos) davam oportunidades iguais aos que, por timidez ou insegurança, não se envolveriam em discussões abertas simultâneas. A obrigatoriedade de participação nos fóruns escritos de maneira assíncrona foi e tem sido essencial para manter o nível de interesse em cada módulo, com a vantagem de poder ser realizada pelos estudantes e docentes respeitando-se seus horários de preferência.

De maneira geral, observamos que a maioria dos alunos aprovou as atividades do curso, o que se pode inferir das respostas aos questionários de avaliação do curso (Tabela 1) e do fato de que mais de $90 \%$ dos alunos matriculados no curso participaram regularmente dos fóruns e demais atividades online (dados não mostrados), muito embora a grande maioria deles tivesse pouca ou nenhuma experiência com ensino à distância. As opiniões dos alunos foram bastante similares, na comparação entre as três turmas finalizadas, e algumas falas dos alunos (obtidas das respostas às questões abertas da avaliação do curso pelos alunos) demonstram que a proposta do curso foi compreendida e aceita pelos discentes, inclusive com o reconhecimento de que há necessidade de uma postura mais ativa do aluno, como ilustram os exemplos seguintes:

“No geral, foi um curso muito bom. Isso porque nunca tivemos no decorrer do curso uma interação tão próxima quanto esta. Essa proximidade proporcionou uma grande ajuda aos alunos que obtiveram algumas dificuldades." (Aluno do primeiro semestre de 2011)

"Bom, eu gostei muito do formato dessa disciplina, similar ao PBL porém semipresencial, pois nesse método é possível fazer um aproveitamento muito maior de todo o conteúdo abordado, pois estamos sempre estudando, já no modo tradicional acabamos por ficar acomodados e estudamos só para a prova." (Aluno do primeiro semestre de 2011)

"O curso [...] é bom para quem quer. Quem participa, pergunta, se interessa, é o melhor curso, pois os professores estão disponíveis, quem não adquire o costume se atrasa, não entende e não gosta." (Aluno do segundo semestre de 2010)

“Achei o curso bom, direcionando o raciocínio clínico e estimulando o aluno a buscar solução para o caso, bem divertido de estudar." (Aluno do primeiro semestre de 2010)
O programa do curso semipresencial de Nefrologia também foi institucionalmente avaliado pela coordenadora pedagógica do curso de Medicina, pois a Faculdade São Lucas busca a qualidade do processo ensino-aprendizagem, perseguindo os padrões avaliativos sistêmicos. O curso foi monitorado de forma especial por fazer parte de um projeto maior de implementação de Educação à Distância da IES, que desenvolve metodologia para EAD em parceria com o Laboratório de Educação a Distância (LED) da Faculdade São Mateus (IES coirmã), para oferta de disciplinas semipresenciais e cursos de graduação e pós-graduação à distância, que aguardam credenciamento do MEC. A atenção especial se justifica também por se tratar de uma proposição de inserção de ferramentas de tecnologias interativas a serviço da educação médica.

A Faculdade São Lucas tem procurado com zelo acompanhar bem de perto e sistematicamente as experiências com a modalidade à distância por acreditar que se trata, segundo Gutierrez e Prieto ${ }^{10}$, "de passar de uma modalidade presa ao ensino e a objetivos preestabelecidos a outra caracterizada pela aprendizagem, pela participação e pela construção do conhecimento" (p. 9). Assim, a instituição tem entendido que, nesta nova concepção - paradigma da aprendizagem - a educação é vista como diálogos abertos, em que a aprendizagem ocorre mediante processos reflexivos, diálogos estes que os aprendizes mantêm consigo mesmos, com os outros, com a ciência e o contexto ${ }^{11}$.

No acompanhamento de mais essa experiência em EAD percebeu-se que este processo traz consigo um movimento em que o grande desafio do professor é garanti-lo sobre o fluxo de energia e da riqueza do processo. Deste modo, a EAD necessita de uma metodologia que proporcione interação e comunicação bilateral, mediatizada por tecnologias adequadas, objetivando a formação do aluno.

Em decorrência dessa visão, no monitoramento do curso semipresencial de Nefrologia, as questões teóricas e técnico-metodológicas foram observadas levando em conta as ferramentas tecnológicas, a motivação, o desempenho e as impressões dos discentes sobre o curso. As duas primeiras turmas experimentaram percursos de aprendizagem por via de ferramentas disponibilizadas no AVA (ambiente virtual de aprendizagem - Moodle), e já se coletaram informações e dados sobre essa experiência. Atualmente, a Coordenação Pedagógica da São Lucas acompanha a experiência da quinta turma, cujos alunos vivenciam percursos de aprendizagem diferentes, com uso de ferramentas internas do AVA e de redes sociais (paciente virtual, grupos de discussão). O acompanhamento objetiva comparar os dados e os resultados. 
Portanto, a experiência do curso semipresencial de Nefrologia se apresenta como um campo de aprendizagem institucional no que diz respeito à mobilização de técnicos para suporte e acompanhamento, de ferramentas tecnológicas e de pesquisa metodológica.

\section{CONCLUSÕES}

A construção de um curso semipresencial de Nefrologia com recursos de Educação à Distância combinados a técnicas de Aprendizagem Baseada em Problemas foi uma solução oportuna para o ensino dessa disciplina a estudantes de graduação em Medicina da região amazônica, onde há carência de docentes qualificados para ministrar essa disciplina da forma tradicional (presencial) e mostrou boa aceitação do corpo discente e da coordenadoria pedagógica da instituição envolvida.

\section{REFERÊNCIAS}

1. Pereira ALF. As tendências pedagógicas e a prática educativa nas ciências da saúde. Cad Saúde Pública. 2003; 19(5):1527-1534.

2. Neufeld VR, Barrows HS. The "McMaster Philosophy": an approach to medical education. J Med Educ. 1974; 49(11):1040-50.

3. Schmidt HG. Foundations of problem-based learning: some explanatory notes. Med Educ. 1993; 27(5):422-32.

4. Boud D, Feletti G. The challenge of problem-based learning. London: Kogan Page; 1997.

5. Barrows H. Problem-based Learning: A Research Perspective on Learning Interaction. New Jersey: Lawrence Erlbaum Associates; 2000.

6. Mennin S, Majoor G. Problem-based learning. The Network - Towards Unity for Health - Position Paper; 2002. Disponível em: http://www.thenetworktufh.org/ publications_resources/positioncontent.asp $\mathrm{id}=7 \& \mathrm{t}=$ Position+Paper.

7. Brasil. Conselho Nacional de Educação. Câmara de Educação Superior. Diretrizes Curriculares Nacionais do Curso de Graduação em Medicina. Resolução CNE/CES N 4 Brasília, 7 de novembro, 1-6; 2001.
8. Brasil. Conselho Nacional de Saúde, Comissão Nacional de Ética em Pesquisa. Perguntas e respostas gerais [online]. CONEP, 2011. [capturado 02 de julho de 2012]; Disponível em: http:/ / conselho.saude.gov.br/web_comissoes/conep/ aquivos/documentos/08_set_perguntas_respostas.pdf

9. Dominguez RLC, Amaral E, Bicudo-Zeferino AM. Conceito Global: um método de avaliação de competência clínica. Rev Bras Educ Med. 2009; 33(1):148-151.

10. Gutierrez F, Prieto D. A mediação pedagógica: educação a distância alternativa. Campinas: Papirus; 1994.

11. Moraes MC. Educação a distância: fundamentos e práticas. Campinas/SP: Editora da UNICAMP; 2002.

\section{CONTRIBUIÇÃO DOS AUTORES}

Leandro Arthur Diehl contribuiu na coleta dos dados com base nos questionários aplicados aos alunos, na análise e compilação dos resultados e na redação do artigo. Carlos Perez Gomes contribuiu na formatação do instrumento de coleta dos dados (questionário), na interpretação dos resultados e na redação do artigo. Gisele de Vasconcelos Sary contribuiu no desenho e implementação do curso e na aplicação do instrumento de coleta dos dados. Hélia Cardoso Gomes da Rocha supervisionou o andamento do curso e contribuiu para a avaliação institucional e na redação do artigo. Luís Marcelo Aranha Camargo orientou o desenho e a implementação do curso e contribuiu para a avaliação institucional, coleta dos dados e redação do artigo. Pedro Alejandro Gordan contribuiu no desenho do projeto de pesquisa, a coleta e análise dos dados, a interpretação dos resultados e contribuiu para a redação do artigo.

\section{CONFLITO DE INTERESSES}

Declarou não haver.

\section{ENDEREÇO PARA CORRESPONDÊNCIA}

Leandro Arthur Diehl

Rua Miguel Elvira Lopes, 69

Residencial Havana - Londrina

CEP 86038-714 - PR

E-mail: leandro@portalendocrino.com.br 